\title{
Lesion Scores, Oocysts Output, Hematological and Histopathological Changes of the 7 Days Life Cycle of Eimeria Tenella in Broilers.
}

Tippayaporn Nonkookhetkhong ( $\nabla$ tippayaporn.n@msu.ac.th )

Mahasarakham University

Thanyakorn Chalalai

Mahasarakham University

\section{Research Article}

Keywords: Eimeria tenella, Lesion scores, oocysts output, hematological, histopathological, broilers

Posted Date: April 7th, 2021

DOl: https://doi.org/10.21203/rs.3.rs-384969/v1

License: (c) (1) This work is licensed under a Creative Commons Attribution 4.0 International License.

Read Full License 


\section{Abstract}

Eimeria tenella is a protozoa which is a causative agent of avian cecal coccidiosis. The disease results in bleeding, diarrhea, weight losses, high morbidity and mortality in chickens. This study investigated lesion scores, oocysts output, hematological and histopathological changes of the 7 days life cycle of $E$. tenella. Fifty-six, broilers were randomly divided into 2 groups of which group 1 were uninfected and group 2 were infected with $2 \times 10^{4} \mathrm{E}$. tenella oocysts. Lesion scores and oocyst output of the infected group were significantly higher than in the uninfected group at 5, 6 and $7 \mathrm{dpi}(p<0.05)$. PCV was significantly lower than in the uninfected group at 3 to $7 \mathrm{dpi}(p<0.05)$. WBC count was significantly higher than in the uninfected group at $4 \mathrm{dpi}(p<0.05)$. Lymphocytes and heterophils were significantly higher than in the uninfected group at $4 \mathrm{dpi}(p<0.05)$. Monocytes were significantly higher than in the uninfected group from 3 to $5 \mathrm{dpi}(p<0.05)$. The developmental stages of $E$. tenella in cecum tissue during the 7 days life cycle included trophozoite at $2 \mathrm{dpi}$, first generation of schizonts at $3 \mathrm{dpi}$, secondary generation of merozoites and schizonts at 4 and $5 \mathrm{dpi}$ and gametocytes and oocysts at 6 and $7 \mathrm{dpi}$. These finding suggest that monocytes were the most effective white blood cell on $E$. tenella infection and secondary generation schizonts was the most pathogenic developmental stage of E. tenella.

\section{Introduction}

Coccidiosis is the most common and costly disease of poultry production worldwide including Thailand. Economic losses are due to high percentage of the mortality and increased feed conversion ratio (Györke et al. 2016). The parasites multiply in the intestinal tract, cause tissue damage, interruption of feeding and digestive processes, bloody diarrhea, reduced weight gain, morbidity and sometimes mortality (James et al. 2009; Hector et al. 2020). The species of coccidian infecting chickens belong to the genus Eimeria, each species causes separate and distinct, recognizable diseases, independent of the other species (Hector et al. 2020). Coccidia species that cause clinical infections include Eimeria necatrix, $E$. brunette, E. acervulina, E. maxima and E. tenella (Donal and Conway 2007). Eimeria tenella causes cecal coccidiosis, in which the cecum become distended with clotted blood; there is bleeding and the liver has been reported to be pale. There is weight losses, high morbidity and mortality (Kaewthamasorn et al. 2015; Sharma et al. 2015). Eimeria tenella infection results in a change in the number of circulating red and white blood cells (Adamu et al. 2013; Akhtar et al. 2015). Differential identification of each species is dependent on zone of intestine parasitized, the gross appearance of the lesion, minimum prepatent time, schizont location of development and location of parasite in the host intestinal epithelium (Donal and Conway 2007). The hematological and histopathological changes in each day of the life cycle of Eimeria tenella will be of benefit for differential diagnosis, treatment and control coccidiosis in chickens. The objective of this study was to investigating lesion scores, oocysts output, hematological and histopathological changes of Eimeria tenella infection in broilers from 1 to 7 days post infection (dpi).

\section{Materials And Methods}

\section{Parasites}


Eimeria tenella oocysts were collected from infected broiler chicken's cecal contents from broiler farms in Roi Et province, Thailand, and maintained at the Faculty of Veterinary Sciences, Mahasarakham University, Thailand. The oocysts underwent sporulation process in $2.5 \%(\mathrm{w} / \mathrm{v})$ potassium dichromate at $30^{\circ} \mathrm{C}$ for 48 hours. The sporulated oocysts were propagated in chickens; five commercial broiler chickens at 21 days old were inoculated with $2 \times 10^{4}$ sporulated oocysts. Then the cecal contents were collected at 7 dpi.

\section{Animals and experimental design}

Fifty-six, one-day-old commercial broiler chickens (Cobb) were obtained from a commercial hatchery. The chickens were randomly divided into 2 groups of 28 chickens each. The chickens in group 1 were not inoculated and group 2 were inoculated with $2 \times 10^{4}$ sporulated oocysts at twenty-one-day-old. Blood samples were collected from four chickens of each group and birds were then euthanized by cervical dislocation at 1, 2, 3, 4, 5, 6 and $7 \mathrm{dpi}$. The cecal tissues were collected from euthanized chickens. The chickens were fed ad libitum before and during the experiment. The experiment was reviewed and approved by the institutional Animal Care and Use Committee, Mahasarakham University (approval number: 033/2019).

\section{Lesion scoring}

The lesion scores of Eimeria tenella were obtained by examining the intestinal lesions of euthanized chickens at 1, 2, 3, 4, 5, 6 and 7 dpi. Scoring of lesions was recorded as described previously of Johnson and Reid (Johnson and Reid 1970): 0 = no sign, 1 = mild lesions, $2=$ Moderate lesions, $3=$ severe lesions and 4 = extremely severe lesions or death.

\section{Oocyst counting}

Fecal samples of each group were collected at 1, 2, 3, 4, 5, 6 and 7 dpi. The oocysts were processed in saturated sodium chloride solution and counted (oocysts/gram of feces) by using McMaster chamber under a light microscope.

\section{Hematological analysis}

Blood samples were collected from wing vein of chickens and transferred immediately into a sterile tube containing the anticoagulant (EDTA). Packed cell volume (PCV) was measured by using microhematocrit tubes and a hematocrit centrifuge, Total white blood count (TWBC) were performed in a 1:20 dilution of blood in Natt and Herrick's solution. Differential white blood cell counts were made by preparation of thin blood smears stained with Wright's stain and identified as lymphocytes heterophils eosinophils monocytes and basophils (Samour 2006).

\section{Histopathological examination}


Cecal tissue samples of infected chickens were fixed in $10 \%$ formalin, then processed embedded in paraffin and trimmed to 3-5 $\mu \mathrm{m}$ using a microtome. Tissue sections were according to histological techniques, stained with hematoxylin and eosin (Awad et al. 2008) and examined under a light microscope.

\section{Statistical analysis}

The lesion scores, oocyst per gram of feces and hematological data were analyzed using Mann-Whitney $\mathrm{U}$ tests with SPSS for windows (SPSS Inc, Chicago). Statistical difference was considered significant at $p$ $<0.05$.

\section{Results}

\section{Clinical signs and lesions}

The uninfected group showed no clinical signs and lesions of disease. After being inoculated with $2 \times 10^{4}$ sporulated oocysts of Eimeria tenella, all chickens of infected group had bloodly diarrhea from 6 to $7 \mathrm{dpi}$. The ceca were distended with clotted blood, but there was no resulting mortality.

\section{Lesion scores}

The Lesion scores of the infected group were significantly higher than the uninfected group at 5,6 and 7 dpi $(p<0.05)$ and were highest at $6 \mathrm{dpi}$. In the uninfected group no coccidia lesions were seen. (Fig. 1).

\section{Oocyst output per gram of feces}

The oocyst output of the infected group was significantly higher than the uninfected group at 5, 6 and 7 $\mathrm{dpi}(p<0.05)$, the number of oocyst output was highest at $7 \mathrm{dpi}$. In the uninfected group, there was no oocyst output in feces. (Fig. 2).

\section{Hematological value}

Hematological value. The packed cell volume of the infected group was significantly lower than the uninfected group at 3, 4, 5, 6 and $7 \mathrm{dpi}(p<0.05)$ and it was lowest at 7 dpi. (Fig. 3).

The total white blood cell count of the infected group was significantly lower than the uninfected group at 1,2 and $7 \mathrm{dpi}(p<0.05)$ but at $4 \mathrm{dpi}$ was significantly higher than those of the uninfected group $(p<$ 0.05). (Fig. 4).

In differential white blood cell counts, the numbers of lymphocytes were significantly higher than uninfected group at $4 \mathrm{dpi}(p<0.05)$. The number of heterophils was significantly lower than the uninfected group at $2 \mathrm{dpi}$ but significantly higher than the uninfected group at $4 \mathrm{dpi}(p<0.05)$. The numbers of monocytes were significantly higher than the uninfected group from 3 to $5 \mathrm{dpi}(p<0.05)$. Eosinophils were significantly lower than in the uninfected group at 5 and $7 \mathrm{dpi}(p<0.05)$ but higher than 
the uninfected group at $6 \mathrm{dpi}$ and basophils were significantly lower than the uninfected group at 5 and 7 dpi $(p<0.05)$. (Fig. 5).

\section{Histopathological examination}

At $1 \mathrm{dpi}$, the cecal tissue of chicken showed mild degeneration of villi epithelium but none of the stages of Eimeria tenella were present in cecal tissue (Fig. 6-i). At 2 dpi, the cecum showed tropozoites in the intestinal glands of cecum (Fig. 6-ii). At $3 \mathrm{dpi}$, the cecum exhibited the first generation of schizonts in the lamina propria and the first generation of merozoites in the first generation of schizonts in the intestinal gland (Fig. 6-iii). At 4 dpi, the cecum showed large clusters of a secondary generation of schizonts and a number of small secondary generation of schizonts in the lamina propria (Fig. 6-iv). At 5 dpi, the cecum revealed loss of villi, necrosis and hemorrhage of cecal mucosa, there were clusters of secondary generation of schizonts and ruptured secondary generation schizonts releasing secondary generation merozoites (Fig. 6-v) which resulted in hemorrhage of cecal mucosa at 5 dpi. At 6 dpi, the cecum showed macrogametocytes and microgametocytes and oocysts in intestinal glands (Fig. 6-vi). At 7 dpi, the cecum showed hemorrhage, infiltration of inflammatory cell as macrophages and clusters of oocysts in submucosa (Fig. 6-vii), clusters of gametocytes and oocysts in intestinal glands (Fig. 6-viii).

\section{Discussion}

The infection of Eimeria tenella in broiler chickens manifested clinically as bloody diarrhea at 6 dpi as previously reported by Kaewthamasorn et al. (2015). Lesion scores and oocysts output were differentially increased from 5 to $7 \mathrm{dpi}$, so the prepatent period of these parasites is 5 days. This result does not agree with Wageha Awadet al. (2018) who found that oocyst shedding started at $6 \mathrm{dpi}$. There were differences of oocyst shedding because of different reproductive rates, differences in the number of schizont stages and the rate at which the stages develop (Cha et al. 2018). The packed cell volumes of the infected group were significantly lower than in the uninfected group at 3, 4, 5, 6 and $7 \mathrm{dpi}(p<0.05)$ because blood vessels were disrupted when the schizonts mature and the merozoites were released (Hector et al. 2020). Blood loss from bloody diarrhea caused reduced erythrocyte count and hematocrit value (Dial 2010) with maximum effect at $7 \mathrm{dpi}$.

The reduction of total white blood cell count in infected chickens at 1 and $2 \mathrm{dpi}$, was due to improper sample handling that may have caused an artifactual decrease in white blood cell count due to blood clotting (Mitchell and Johns 2008). Circulating concentrations of leukocytes are depressed in birds maintained in captivity or stress, due to decreases in both the percentage and number of heterophils (Scanes 2015). Leukocytosis at 4 dpi was due to the increase of lymphocytes and heterophils. Leukocytosis is often associated with inflammatory diseases, infectious diseases or stress.

Moreover, the most pathogenic stage is secondary generation schizonts which mature at $4 \mathrm{dpi}$ (Hector et al. 2020). After that the total white blood cell counts were reduced because they migrate to the tissues to reparation and regulation of the immune response (Dial 2010). 
Heterophils are the first leukocytes to migrate from the blood to infected sites for killing pathogens. (Rosales et al. 2016; Sukumaran et al. 2005). Heterophils exhibit superior ability to monocytes, both to phagocytize and to kill bacteria. Moreover, the severity of the leukocytosis associated with heterophilia may correlate with the severity of the disease (Scanes 2015). The major difference present of leukocytes was the numbers of monocytes. These results suggest that monocytes were the most effective white blood cells on Eimeria tenella infection and monocytosis associated with Eimeria tenella infection. This agrees with another report on Eimeria bovis infection (Taubert et al. 2009).

Monocytes are phagocytic and once they enter into tissues they are transformed into macrophages ( Mitchell and Johns 2008). Moreover, monocytes and macrophages function via chemotaxis, which involves migration toward an inflammatory gradient (Qureshi 2003).

Histopathological lesions in this study showed loss of cecal villi, necrosis and hemorrhage of cecal mucosa as has been reported in previous studies (Sharma et al. 2015; Adamu et al 2013; Abdelrazek et al 2020). The developmental stage of Eimeria tenella in cecum tissue at 7 days life cycle includes, trophozoite at $2 \mathrm{dpi}$, first generation of schizonts at $3 \mathrm{dpi}$, secondary generation of merozoites and schizonts at 4 and $5 \mathrm{dpi}$ and gametocytes and oocysts at 6 and $7 \mathrm{dpi}$. These findings were similar to the generalized life cycle of Eimeria spp. in chickens in (Donal and Conway 2007). Clusters of large schizonts develop deep in the lamina propria, due to the blood vessels disruption when the merozoites are released (McKenzie et al. 1985), in agreement with our results of lesion scores.

The developmental stage of Eimeria tenella which affected the pack cell volume and circulating white blood cells was the secondary generation schizonts, of which the most pathogenic stage is when mature at $4 \mathrm{dpi}$ (Hector et al. 2020). Macrophages significantly infiltrate the cecal mucosa to phagocytosis of the pathogen at $7 \mathrm{dpi}$. Similar results have been reported for Eimerial infection in calves (Taubert et al. 2009) and were related to the reduction of white blood cell count because of loss of white blood cells into cecal tissues (Abdelrazek et al. 2020).

\section{Conclusion}

In this study, monocytes were found to be the most effective white blood cell on Eimeria tenella infection. The most pathogenic developmental stage of Eimeria tenella which was effective on lesion scores, hematological and histopathological changes was secondary generation schizonts.

\section{Declarations}

\section{Author contributions}

All authors contributed to the study conception and design. Material preparation, data collection and analysis were performed by Tippayaporn Nonkookhetkhong and Thanyakorn Chalalai. The first draft of the manuscript was written by Tippayaporn Nonkookhetkhong and all authors commented on previous versions of the manuscript. All authors read and approved the final manuscript. 
Acknowledgements

This work was financially supported by the faculty of Veterinary Sciences, Mahasarakham University 2018. We would like to thank Asst. Prof. Dr. Amornrat Juasook and Miss Sukhkamon Ketphonthong for their support.

\section{References}

1. Abdelrazek Y, Desouky MAM, Khaled Sultan, Nagwa M. Elhawary, Noha Ibrahim Ammar (2020)

2. Levamisole Hydrochloride as Immunostimulant Drug Synergies the Effect of Eimeria tenella Labmade Vaccine: Experimental Trial. . Asian Journal of Animal Sciences. 14:54-60

3. Adamu M, Boonkaewwan C, Gongruttananun N, Vongpakorn M (2013) Hematological, biochemical and histopathological changes caused by Coccidiosis in chickens. Kasetsart Journal - Natural Science. 47:238-46

4. Akhtar M, Awais MM, Anwar MI, Ehtisham-ul-Haque S, Nasir A, Saleemi MK (2015) The effect of infection with mixed Eimeria species on hematology and immune responses following Newcastle disease and infectious bursal disease booster vaccination in broilers. Vet Q. 35(1):21-6

5. Awad W, Ghareeb K, Böhm J. (2008) Intestinal structure and function of broiler chickens on diets

6. supplemented with a synbiotic containing Enterococcus faecium and oligosaccharides. Int J Mol Sci. 9(11):2205-16 DOI: 3390/ijms9112205

7. Cha JO, Zhao J, Yang MS, Kim WI, Cho HS, Lim CW (2018) Oocyst-Shedding Patterns of Three Eimeria

8. Species in Chickens and Shedding Pattern Variation Depending on the Storage Period of Eimeria tenella J Parasitol. 104(1):18-22 DOI: 10.1645/16-132

9. Dial AJRaSM (2010) Abnormalities in the Red and Whites Blood Cell Populations. In: Clinical Pathology for the Veterinary Team, Willey-Blackwell, USA, pp 45-74

10. Donal P, Conway MEM (2007) Poultry Coccidiosis: Diagnostic and Testing Procedures, WileyBlackwell, USA

11. Györke A, Kalmár Z, Pop LM, uteu OL (2016) The economic impact of infection with Eimeria spp. in

12. broiler farms from Romania. Revista Brasileira de Zootecnia. 45:273-80 http://dx.doi.org/10.1590/S1806-92902016000500010

13. Hector M, Cervantes LRM, Mark CJ (2020) Coccidiosis. In: Diseases of Poultry, 14 edn. John Wiley \&

14. Sons Inc., USA, pp 1193-217

15. James GB, Hany ME, Tosson AM (2009) Avian coccidiosis: the basic pathology to control. Egypt. Soc.

16. Parasitol. 39(1):85-98

17. Johnson J, Reid WM. (1970) Anticoccidial drugs: Lesion scoring techniques in battery and floor-pen 
18. experiments with chickens. Experimental Parasitology. 28(1):30-6 https://doi.org/10.1016/00144894(70)90063-9

19. Kaewthamasorn M, Charoenvisal N, Chansiripornchai N (2015) Efficacy of Salinomycin, Robenidine and Decoquinate Against Infection with Eimeria Species Field Isolate in A Densely Populated Broiler Farm in Thailand. Thai journal of Veterinary Medicine. 45:247-53

20. McKenzie ME, Johnson J, Long PL (1985) Lethality of intestinal tissue extracts from Eimeria-infected 21. Parasitology. 90(3):565-72. DOI: 10.1017/s0031182000055554

22. Mitchell EB, Johns J (2008) Avian hematology and related disorders. Vet Clin North Am Exot Anim 23. 11(3):501-22

24. Qureshi MA (2003) Avian macrophage and immune response: an overview. Poult Sci. 82(5):691-8

25. Rosales C, Demaurex N, Lowell CA, Uribe-Querol E (2016) Neutrophils: Their Role in Innate and Adaptive Immunity. Journal of Immunology Research. 1469780 https://doi.org/10.1155/2016/1469780

26. Samour J. (2006) Diagnostic value of hematology. Clinical Avian Medicine. 587-610

27. Scanes CG (2015) Blood. In: Scanes CG (ed) Sturkie's Avian Physiology, 6 edn. Academic Press, San Diego, pp. 167-91

28. Sharma S, Azmi S, Iqbal A, Nasirudullah N, Mushtaq I (2015) Pathomorphological alterations associated with chicken coccidiosis in Jammu division of India. Journal of Parasitic Diseases. 39(2):147-51

29. Sukumaran B, Carlyon JA, Cai J-L, Berliner N, Fikrig E (2005) Early transcriptional response of human 30. neutrophils to Anaplasma phagocytophilum Infect Immun. 73(12):8089-99 DOI: 10.1128/IAl.73.12.8089-8099.2005

31. Taubert A, Behrendt JH, Sühwold A, Zahner H, Hermosilla C (2009) Monocyte- and macrophagemediated immune reactions against Eimeria bovis. Vet Parasitol. 164(2-4):141-53 DOI: 1016/j.vetpar.2009.06.003

\section{Figures}

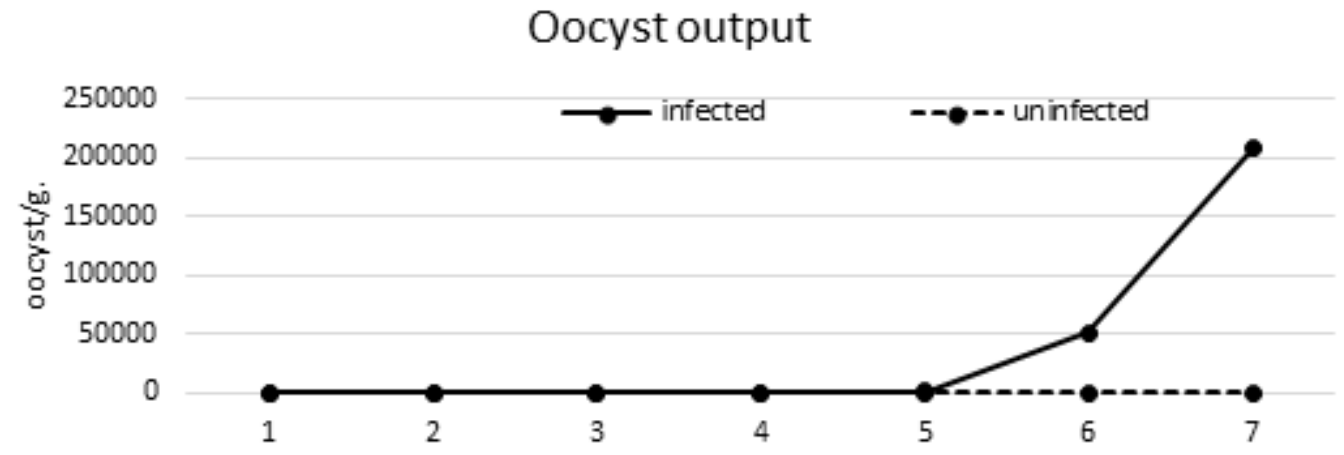




\section{Figure 1}

The mean ( \pm standard deviation) of lesion scores. Y-axis=the mean of lesion score, $X$-axis=dpi.

\section{Lesion scores}

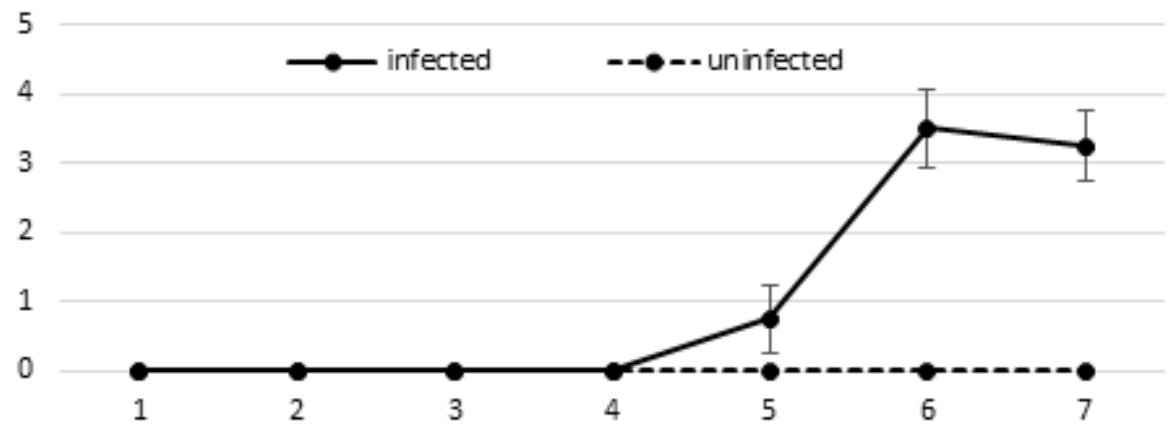

\section{Figure 2}

The mean numbers ( \pm standard deviation) of oocyst output. Y-axis=the mean numbers of oocysts output (oocyst/g.), X-axis=dpi.

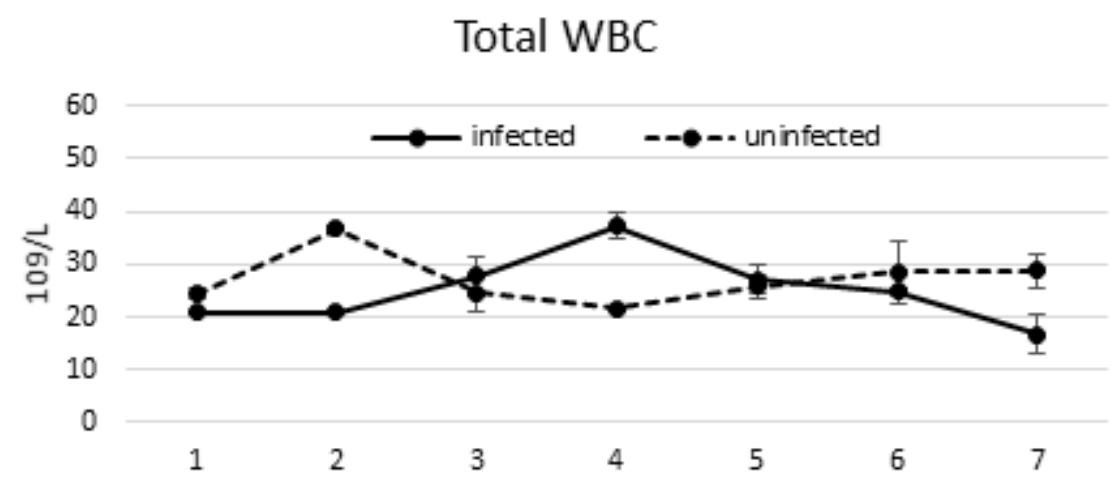

\section{Figure 3}

The mean ( \pm standard deviation) of PCV. Y-axis=The mean of PCV (\%), X-axis=dpi. 


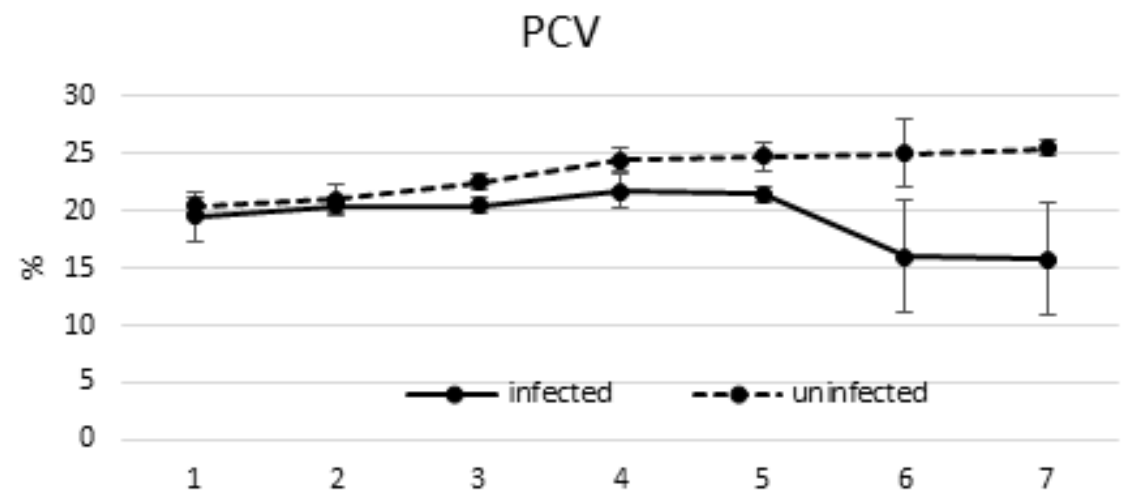

Figure 4

The mean ( \pm standard deviation) of total WBC count Y-axis=The mean numbers of total WBC $(109 / \mathrm{L}), \mathrm{X}$ axis=dpi. 

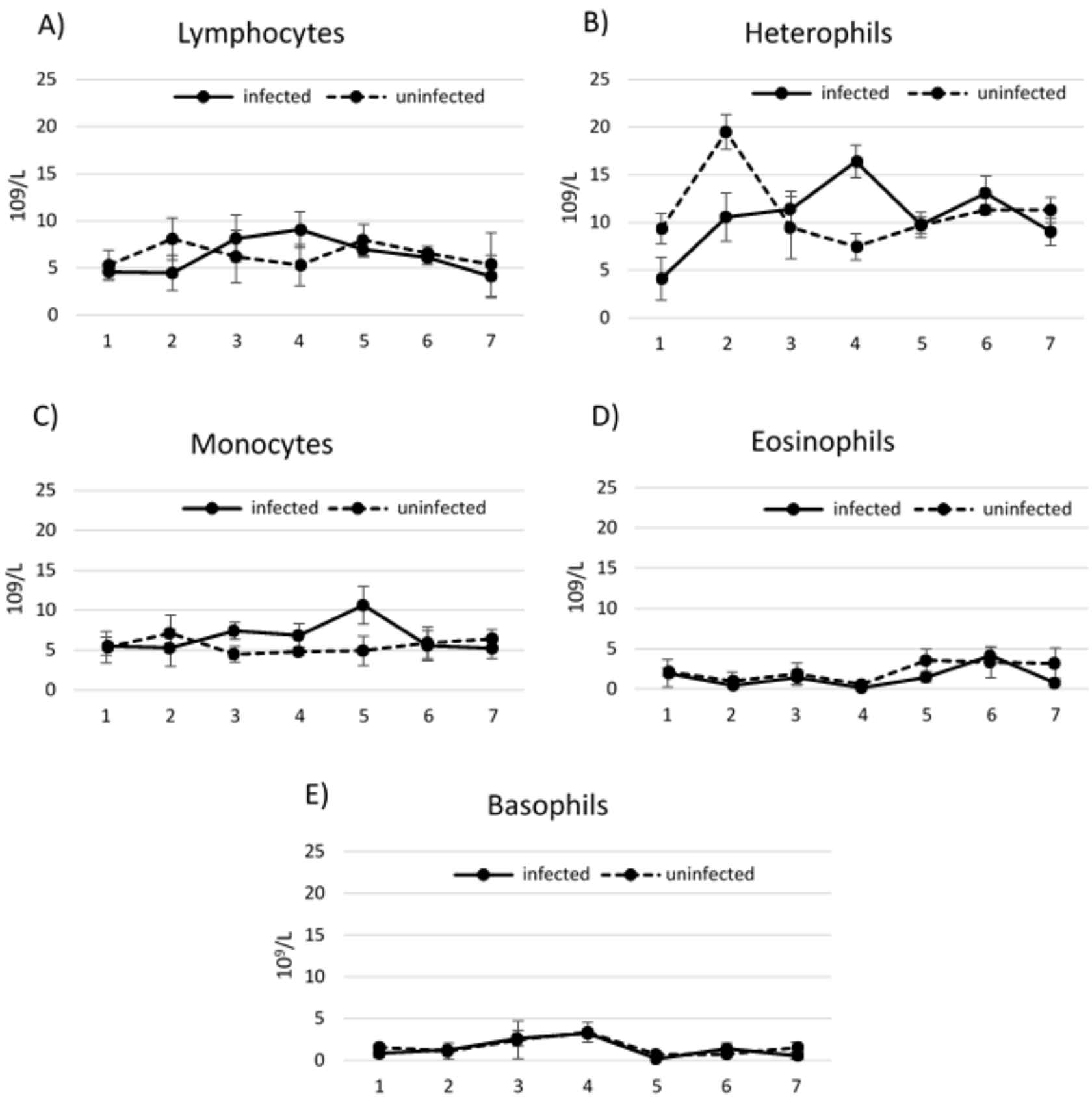

Figure 5

Differential white blood cell counts of experimental chickens from 1-7 dpi. The mean numbers ( \pm standard deviation) of lymphocytes $(A)$, heterophils $(B)$, monocytes $(C)$, eosinophils $(D)$ and basophils $(E)$. $Y$ axis=the mean numbers of white blood cell $(109 / L), X$-axis=dpi. 

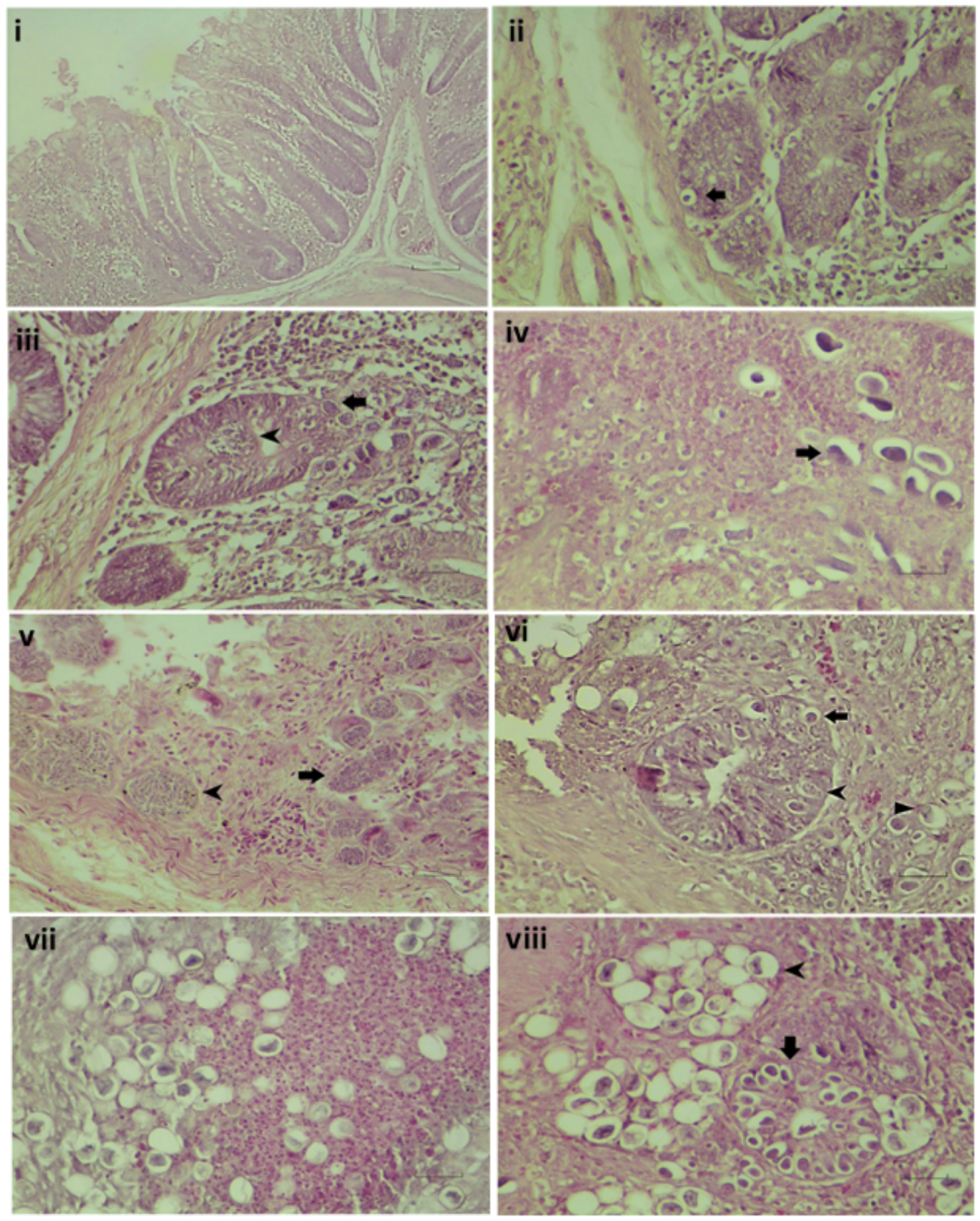

Figure 6

Section of the cecal tissue of chicken from 1 to 7 days after E. tenella infection. (i) $1 \mathrm{dpi}$, there were not any stages of E. tenella in cecal tissue (10x), (ii) 2 dpi, tropozoites in intestinal glands of cecum (arrow) (40x), (iii) $3 \mathrm{dpi}$, first generation of schizonts in lamina propria (arrow) and first generation of merozoites in first generation of schizonts in intestinal glands of cecum (pointed arrow) (40x), (iv) 4 dpi, clusters of large secondary generation of schizonts (arrow) and the numbers of small secondary generation of 
schizonts in lamina propria (40x), (v) $5 \mathrm{dpi}$, clusters of secondary generation of schizonts (arrow) and ruptured secondary generation of schizonts releasing secondary generation merozoites (pointed arrow) (40x), (vi) 6 dpi, macrogametocytes (arrow), microgametocytes (pointed arrow) and oocysts in intestinal glands (arrow head) (40x) and (vii-viii) $7 \mathrm{dpi}$, hemorrhage, infiltration of macrophages and cluster of oocysts in submucosa, clusters of gametocytes (arrow) and oocysts (pointed arrow) in intestinal glands $(40 x)$. 